\title{
Construção de sentidos em práticas estratégicas: estudo comparativo em duas instituições de ensino superior paranaenses
}

\author{
Sensemaking in strategic practices: comparative study in two \\ higher education institutions from Paraná, Brazil
}

Ludmilla Meyer Montenegro[a], Yára Lúcia Mazziotti Bulgacov ${ }^{[b]}$

[a] Mestre em Administração pela Universidade Federal do Paraná, Curitiba, PR - Brasil, e-mail: ludmilla2907@gmail.com

[b] Doutora em Educação pela Universidade Estadual Paulista Júlio de Mesquita, professora da Universidade Positivo e

Universidade Federal do Paraná, Curitiba, PR - Brasil, e-mail: ybulgacov@gmail.com

\section{Resumo}

Com o intuito de lançar um olhar mais humano e mais próximo do fenômeno investigado, este trabalho tem como objetivo compreender os sentidos individuais e coletivos construídos pelos atores nas práticas estratégicas imersas em processos estratégicos a partir da identificação e descrição das atividades individuais e coletivas que compõem essas práticas. 0 referencial teórico tem como base algumas considerações sobre conteúdo e processo estratégico, a perspectiva da estratégia enquanto prática e as concepções do sensemaking. 0 estudo foi realizado em dois cursos de graduação em Administração de duas IES (Instituição de Ensino Superior) do Estado do Paraná, a UFPR e a FAE Centro Universitário. Trata-se de uma pesquisa qualitativa de tipo exploratória e a coleta de dados foi realizada por meio de informações localizadas nos sites das IES, documentos, entrevistas semiestruturadas e em profundidade com os praticantes identificados (15 na UFPR e 19 na FAE) e observação não-participante. Foi desenvolvida uma análise narrativa para cada caso, porém o foco deste artigo é na análise comparativa dos casos. Com relação aos resultados, foi possível observar que os cursos diferem no que diz respeito aos seus conteúdos e processos estratégicos e ao processo de sensemaking em relação às práticas estratégicas, inclusive dentro das categorias de praticantes identificadas em cada caso. Ao final, conclui-se que, o grau de envolvimento e comprometimento dos praticantes (strategizing) caracteriza o seu processo de sensemaking.

Palavras-chave: Sensemaking. Estratégia enquanto prática. Processo estratégico. Instituição de ensino superior.

\footnotetext{
Abstract

In order to launch a more humane and close look to the researched phenomenon, this paper aims to understand the individual and collective meanings constructed by the actors on the strategic practices immersed in strategic processes based on the identification and description of the individual and collective activities that compose these practices. The theories used were: considerations of strategic content and process, strategy-as-practice and sensemaking. The study was undertaken in two business courses of two higher education institutions in the state of Parana, UFPR
} 
and FAE. It is an exploratory qualitative research and the data were collected by gathering information from the sites of the institutions, documents, in-depth semistructured interviews with the identified practitioners (15 at UFPR and 19 at FAE) and nonparticipant observation. About the data analysis, a narrative analysis was written for each case, but the focus of this paper is on the comparative analysis which was done afterwards. Some of the results: it was possible to observe that the two courses differ in matters concerning their strategic contents and processes and on the way that the process of sensemaking related to the strategic practices happens, even in the practitioners categories identified for each case. At last, it was possible to imply that the degree of involvement and compromise of the practitioners (strategizing) characterize their process of sensemaking.

Keywords: Sensemaking. Strategy-as-practice. Strategic process. Higher education institution.

\section{Introdução}

Sabe-se que estudos com abordagens funcionalistas e com visões tradicionais da estratégia ainda é uma realidade bastante atual, porém tem-se observado uma crescente publicação de estudos com perspectivas epistemológicas diferentes da funcionalista, bem como com abordagens mais recentes do entendimento da estratégia.

A estratégia enquanto prática, perspectiva adotada na presente pesquisa, é um exemplo de abordagem mais recente em que se percebe a preocupação em revelar questões implícitas por meio de uma maior aproximação do fenômeno investigado. Contudo, é importante ressaltar que, nessa perspectiva, teorias e conceitos tradicionais sobre estratégia não são deixados de lado; pelo contrário, são considerados importantes, principalmente porque foi a partir deles que se pôde construir um entendimento sobre estratégia enquanto prática, sobre sua relevância para as organizações e por que esses entendimentos permeiam o campo da prática e o repertório dos praticantes. Tal fato é constatado quando se observa que a estratégia enquanto prática não trata de dicotomias conteúdo/processo, formulação/implementação, estratégia deliberada/estratégia emergente, etc.

Diante desta perspectiva que privilegia o cotidiano do fazer estratégia - a estratégia enquanto prática surgiu a necessidade de se atrelar, a essa abordagem, um apoio teórico com características similares - humano, interpretativo, social - para que o emaranhado teórico que sustenta a presente pesquisa pudesse se fortalecer. Com isso, optou-se por utilizar as concepções teóricas do sensemaking.
Assim, nesta pesquisa defende-se o pressuposto que é importante para a "eficácia" da estratégia: levar em consideração como, no dia a dia, acontecem as práticas estratégicas, quem são seus praticantes, como estes atribuem significados a essas práticas e como os significados são apropriados, construídos e reconstruídos individual e coletivamente. Um outro pressuposto desta pesquisa é que se acredita que a apropriação cultural e a apropriação da estratégia pelo indivíduo/grupo/organização sejam dimensões fundamentais da "eficácia" da estratégia em uma organização; ou seja, defende-se que, dependendo das práticas realizadas e das formas de apropriação de sentidos comuns dos praticantes, a estratégia será bem sucedida ou não.

O campo empírico escolhido para esta pesquisa foram IES, uma pública (UFPR) e outra privada (FAE). Os casos estudados foram os cursos de graduação em Administração.

Com base nas duas perspectivas teóricas, nos pressupostos e no campo empírico escolhidos, traçou-se o objetivo do trabalho: compreender os sentidos individuais e coletivos construídos pelos atores nas práticas estratégicas (imersas nos processos estratégicos dos cursos de graduação em Administração da UFPR e da FAE - duas instituições de ensino superior do estado do Paraná) a partir da identificação e descrição das atividades individuais e coletivas que compõem essas práticas.

Este trabalho está estruturado da seguinte forma: além desta introdução, fez-se um breve delineamento da base teórica utilizada; em seguida, abordou-se a metodologia; depois, a análise dos dados, seguida da discussão dos resultados e considerações finais e, por fim, as referências bibliográficas utilizadas no estudo. 


\section{Referencial teórico}

0 presente trabalho tem como base, essencialmente, duas abordagens teóricas. A abordagem da estratégia enquanto prática, desenvolvida principalmente pelos trabalhos de Whittington (2006), Jarzabkowski (2005) e Johnson et al. (2007) e a construção de sentidos (sensemaking) de Weick (1995). Além disso, foram feitas algumas considerações sobre conteúdo e processo estratégico, visto que, apesar de serem questões abordadas por visões mais tradicionais da estratégia, são relevantes para o entendimento da estratégia enquanto prática e para o escopo desta pesquisa.

\section{Considerações sobre conteúdo e processo estratégico}

$\mathrm{Na}$ abordagem da estratégia enquanto prática, apesar de não se considerar a dicotomia conteúdo/ processo, é a partir de concepções de conteúdo e de processo que se observou a necessidade de estudar a estratégia enquanto uma prática social, no intuito de tratar a estratégia como um todo e não de maneira fragmentada. Autores que estudam processo estratégico, Chakravarthy e White (2002), por exemplo, identificam um foco muito específico no processo e a desconsideração da estratégia em si (preocupação dos estudiosos de conteúdo), ou seja, o fenômeno estudado estava sendo posto em segundo plano. Já alguns estudos sobre conteúdo estratégico, por sua vez, não aprofundam questões relacionadas a como se chega nas estratégias, às questões sócio-históricas e às interações dos envolvidos com a estratégia. Diante dessas questões, são propostas algumas considerações tanto sobre conteúdo quanto sobre processo para que se tenha uma melhor compreensão da abordagem escolhida neste estudo.

Os estudos sobre conteúdo estratégico estão direcionados a saber quais estratégias serão utilizadas pelas organizações. Diante disso, o conteúdo estratégico está relacionado àquilo que levará a organização a obter um desempenho econômico e financeiro a partir das atividades que desenvolve, tais como posição de mercado em relação aos concorrentes, mercados de atuação e produtos que insere nesses mercados; ou seja, o conteúdo estratégico preocupa-se com a definição de produto e mercado nas organizações. Assim, nesta perspectiva, a estratégia é definida como um conjunto de regras que estabelece direções gerais para o crescimento e o desenvolvimento da posição da empresa (ANSOFF, 1990). Outro autor que desenvolveu estudos bastante relevantes no campo do conteúdo estratégico é o economista Michael Porter. A abordagem porteriana preocupa-se em saber qual a melhor posição de produtos em relação aos mercados para que a empresa possa estar em uma posição competitiva perante seus concorrentes.

Ao tratar de processo estratégico o olhar é principalmente voltado para dentro das empresas porque essa abordagem se preocupa em entender como as estratégias da empresa são formadas. As questões internas são o foco da pesquisa em processo estratégico.

Um aspecto interessante das pesquisas em processo estratégico é que, por se tratar de processo, é comum tratar a estratégia como um processo em si (PETTIGREW, 1992), uma vez que a ideia de processo remete a movimento e dinamismo. 0 termo processo é bastante amplo, impossibilitando uma definição específica. Alguns pesquisadores fazem recortes para analisar um processo específico; outros consideram o processo como algo mais abrangente que está sempre acontecendo. Weick (1995), por exemplo, considera o processo de sensemaking como ongoing: contínuo, dinâmico. Não tem início, meio ou fim. Porém, por questões metodológicas de uma pesquisa empírica, é necessário fazer um recorte e especificar o processo estudado.

Já autores como Chakravarthy e White (2002) possuem uma visão mais integradora de conteúdo e processo, uma vez que, para eles, "desempenho empresarial, estratégia, decisões, ações, contexto de negócios e organizacional, todos mudam através do tempo e influenciam um ao outro dinamicamente" (CHAKRAVARTHY; WHITE, 2002, p. 183). É como se um estivesse associado ao outro, e não seria coerente tratá-los separadamente. Visão esta que também corrobora a perspectiva da estratégia enquanto prática.

\section{Estratégia enquanto prática}

A abordagem da estratégia enquanto prática é uma perspectiva relativamente recente de se estudar estratégia. Por tratar a estratégia como uma prática social que acontece nas organizações, essa abordagem preocupa-se em analisar as atividades humanas 
relacionadas às estratégias, bem como aqueles que realizam essas atividades, ou seja, os atores que estão envolvidos com as estratégias da organização. Nessa perspectiva, enfatiza-se que a estratégia não é algo que as organizações têm, mas algo que as pessoas das organizações fazem (JOHNSON et al., 2007).

É importante deixar claro que um dos focos da estratégia enquanto prática são as microatividades que, apesar de geralmente invisíveis às pesquisas tradicionais de estratégia, podem ter consequências significativas para as organizações e para aqueles que lá trabalham (JOHNSON; MELIN; WHITTINGTON, 2003 apud JOHNSON et al., 2007).

Um conceito mais abrangente de estratégia enquanto prática proposto por Johnson et al. (2007, p. 7) diz que "a estratégia enquanto prática preocupa-se com o que as pessoas fazem em relação à estratégia e como isso é influenciado por e influencia seu contexto organizacional e institucional". Essa definição enfatiza a questão do ambiente e, principalmente, do macrocontexto. Sabe-se da importância do macrocontexto na perspectiva da estratégia enquanto prática; porém, como se trata de uma abordagem que permite ser analisada por meio de diversos focos, convém enfatizar que o foco institucional não é o da presente pesquisa.

De acordo com Jarzabkowski (2005, p. 7, tradução nossa):

a linha de pesquisa da estratégia enquanto prática está preocupada com a estratégia enquanto uma atividade dirigida, realizada socialmente e construída através das ações e interações de múltiplos atores. De forma abrangente, essa linha de pesquisa possui três pontos focais, e cada um deles oferece um anglo diferente para se examinar a estratégia enquanto prática: prática, praticantes e práticas.

Tendo em vista a importância dessas três questões apontadas por Jarzabkowski (2005), convém evidenciá-las: (1) a prática é a estratégia enquanto fluxo de atividade organizacional que incorpora conteúdo e processo, deliberação e emergência, pensar e agir, como partes recíprocas, entrelaçadas e frequentemente não distinguíveis de um todo quando são observadas de perto; (2) os praticantes são vistos como indivíduos sociais, interagindo com as circunstâncias sociais envolvidas no fazer estratégia; e (3) práticas são aquelas tradições, normas, regras e rotinas através das quais o trabalho da estratégia é construído (artefatos socioculturais nos quais o fazer estratégia ocorre).

As práticas estratégicas são multiníveis, pois em um nível elas podem ser específicas da organização, incorporadas a rotinas, procedimentos operacionais e culturas que formam maneiras locais do fazer estratégia. Contudo, a teoria da prática enfatiza as práticas extraorganizacionais também. Tais práticas derivam dos campos sociais mais amplos ou dos sistemas nos quais uma organização específica está imersa (WHITTINGTON, 2006). Este trabalho tem como foco as práticas estratégicas intraorganizacionais, específicas da organização estudada e que são incorporadas a sua rotina e cultura, o que justifica, mais uma vez, o foco no microcontexto.

Uma questão bastante relevante em relação às práticas é que, apesar de estarem diretamente ligadas a rotinas, muitas vezes incorporadas a elas, isso não significa que elas sejam imutáveis, pois são diversas, variáveis e podem ser combinadas e alteradas de acordo com a utilidade para a qual elas são colocadas e com a maneira pela qual elas alteram o fluxo de atividade no qual elas são utilizadas (BALOGUN; JOHNSON, 2004 apud JARZABKOWSKI; BALOGUN; SEIDL, 2007).

Jarzabkowski (2005) define as práticas como administrativas, discursivas e episódicas. As práticas administrativas estão relacionadas à organização e à coordenação da estratégia, tais como mecanismos de planejamento, orçamentos, previsões, sistemas de controle e indicadores de desempenho. Já as práticas discursivas são as que oferecem recursos linguísticos, cognitivos e simbólicos para a interação sobre a estratégia. Essas práticas são relevantes no sentido de que muitos estudos mostram que a estratégia é mediada pela linguagem que os estrategistas usam. E, por fim, as práticas episódicas são aquelas que criam oportunidades para e organizam a interação entre os praticantes no fazer estratégia. Essas práticas podem ser formais - reuniões de planejamento estratégico, workshops e reuniões fora da organização -, e também podem ser informais e não oficiais (HENDRY; SEIDL, 2003).

\section{Sensemaking e organizing}

Existem diferentes definições para o termo sensemaking. Alguns autores, como, por exemplo, Starbuck e Milliken (1988, apud WEICK, 1995), 
definem sensemaking como uma forma de colocar estímulo em um quadro de referência. A ideia é que, quando as pessoas colocam estímulos em quadros de referência, isso permite que elas compreendam, entendam, expliquem, atribuam, extrapolem e prevejam. Então, tomando como exemplo a estratégia, que é objeto de interesse desta pesquisa, pode-se dizer que as pessoas utilizam a estratégia como um quadro de referência (que envolve fornecimento, produção, síntese, manipulação e difusão de informação) de tal forma que dê significado, propósito e direção para a organização.

Para Gioia e Chittipeddi (1991), sensemaking trata da construção e reconstrução de significado pelas partes envolvidas à medida que elas tentam desenvolver um quadro de referência significativo para entender a natureza do processo em questão.

Já Sackman (1991 apud WEICK, 1995) fala de mecanismos de sensemaking que os atores das organizações utilizam para atribuir significados a eventos. Esses mecanismos incluem os padrões e regras para perceber, interpretar, acreditar e agir que são tipicamente usados num contexto cultural.

É importante ressaltar que sensemaking e interpretação não são sinônimos, já que a interpretação pode ser entendida como um componente do sensemaking (WEICK, 1995). Então, pode-se dizer que o processo de sensemaking é essencialmente interpretativo, mas é mais abrangente por envolver outras questões. Isso pode ser explicado quando se diz que o sensemaking está relacionado às maneiras pelas quais as pessoas geram o que elas interpretam, a interpretação refere-se àquilo que está sendo interpretado e o sensemaking preocupa-se com o como.

Outro aspecto relevante do sensemaking é que trabalhar com a ideia de sensemaking é apreciar que a pequenez não equivale à insignificância. Estruturas pequenas e momentos curtos podem ter grandes consequências. Além disso, fazer sentido é conectar o abstrato com o concreto (WEICK; SUTCLIFFE; OBSTFELD, 2005). Por isso, Weick (1995) diz que a ideia do sensemaking é tentar tornar tangível o subjetivo.

Existem algumas propriedades que compõem o sensemaking: (1) baseado na construção da identidade - um sensemaker nunca age sozinho porque sua identidade é construída a partir da interação com os outros, o que caracteriza um tipo de identidade coletiva; (2) caráter retrospectivo - a criação de significado é tida como um processo de atenção àquilo que já ocorreu, então a atenção é direcionada "para trás" a partir de um ponto específico no tempo e, como o texto para ser interpretado já ocorreu, e é só uma memória, qualquer coisa que afetar o "processo de lembrar" irá afetar o sentido que é dado a essas memórias; (3) criado em ambientes sensatos - para Weick, não há um ambiente monolítico e fixo que existe separadamente das pessoas. As pessoas fazem parte de seus próprios ambientes criados; (4) social - o sensemaking nunca é solitário porque o que uma pessoa faz internamente é contingente aos outros. Mesmo a inação é contingente aos outros; (5) dinâmico - o sensemaking não tem um ponto de início. Isso se dá porque as pessoas estão sempre no meio de coisas, de fluxos contínuos; (6) focado em e por dicas extraídas - dicas extraídas são estruturas familiares e simples, consideradas como "sementes" a partir das quais as pessoas desenvolvem um sentido mais amplo sobre o que pode estar ocorrendo; e (7) guiado pela plausibilidade em vez de pela precisão - o sensemaking não é sobre verdade nem certeza, mas sobre a reformulação contínua de uma estória emergente para que ela se torne mais compreensiva.

De acordo com Weick (1979), o processo de sensemaking realizado por atividades coletivas pode ser denominado de organizing.

O sensemaking nas organizações baseia-se nas seguintes perguntas: Como que alguma coisa tornou-se um evento para os membros organizacionais? 0 que um evento significa? (WEICK; SUTCLIFFE; OBSTFELD, 2005). Quando se tem uma preocupação com o que está realmente acontecendo em uma determinada situação e as pessoas questionam-se sobre como devem agir, surge a necessidade de realizar um processo de sensemaking para "desvendar" essas questões.

A relevância do sensemaking nas organizações pode ser constatada através da compreensão de que, a partir do momento em que as pessoas da organização buscarem construir um sentido compartilhado sobre determinada questão ou processo (processo que irá, consequentemente, gerar um melhor entendimento do ambiente no qual estão inseridas), elas estarão mais bem preparadas para enfrentar as situações de ambiguidade que são uma realidade no âmbito organizacional.

Weick tem uma preferência pelos verbos no gerúndio, pois eles indicam continuidade, movimento. Por isso, utiliza os termos sensemaking e organizing. Seguindo essa lógica e salientando a coerência entre 
as teorias abordadas nesta pesquisa, Jarzabkowski, Balogun e Seidl (2007), na perspectiva da estratégia enquanto prática, referem-se ao fazer estratégia como strategizing, pois também se trata de um processo contínuo, que envolve uma interação entre prática, praticantes e práticas.

\section{Contextualização do curso de graduação em administração no Brasil}

A história dos cursos superiores de Administração no Brasil começa no início do século, simultaneamente com um longo processo de definição sobre quais as fronteiras do campo do saber administrativo. Por mais de seis décadas, o ensino das ciências administrativas se confundiu com o das ciências econômicas, até a definição do currículo mínimo em 1966. Os primeiros cursos de Administração no Brasil foram ofertados pelas instituições: (1) Escola Superior de Administração de Negócios (ESAN) em São Paulo, 1941; (2) Escola Brasileira de Administração Pública (EBAP/FGV) Getúlio Vargas, Rio de Janeiro, 1952; (3) Faculdade de Ciências Econômicas da Universidade Federal de Minas Gerais (FCE/UFMG), Belo Horizonte, 1952; (4) Escola de Administração de Empresas de São Paulo (EAESP/FGV), São Paulo, 1954; (5) Escola de Administração (EAUFBA), Salvador, 1959; (6) Faculdade de Economia e Administração (FEA/USP), São Paulo, que, apesar de ter sido criada em 1946, só veio oferecer o curso de Administração em 1963; (7) Instituto de Administração (UFRGS), Porto Alegre, 1966 (SILVA; FISCHER, 2008).

O curso de graduação em Administração no Brasil é devidamente regulamentado de acordo com as seguintes especificações das diretrizes curriculares (RESOLUÇÃO CNE/CES n. 4 de 13 de julho de 2005): (1) curso/denominação: Administração; (2) sem habilitação e (3) modalidade: bacharelado.

No art. $3^{\circ}$ das diretrizes curriculares (RESOLUÇÃO CNE/CES n. 4, de 13 de julho de 2005) está descrito o perfil desejado do formando:

o curso de Graduação em Administração deve ensejar, como perfil desejado do formando, capacitação e aptidão para compreender as questões científicas, técnicas, sociais e econômicas da produção e de seu gerenciamento, observados níveis graduais do processo de tomada da decisão, bem como para desenvolver gerenciamento qualitativo e adequado, revelando a assimilação de novas informações e apresentando flexibilidade intelectual e adaptabilidade contextualizada no trato de situações diversas, presentes ou emergentes, nos vários segmentos do campo de atuação do administrador (RESOLUÇÃO CNE/CES n. 4, de 13 de julho de 2005).

De acordo com o perfil sugerido nas diretrizes curriculares, observa-se que o aluno de um curso de graduação em Administração deve, ao longo do curso, desenvolver competências e habilidades adequadas para atuar como um administrador. Convém salientar que essas competências e a habilidades também estão descritas nas diretrizes curriculares (RESOLUÇÃO CNE/CES n. 4, de 13 de julho de 2005, art. $4^{\circ}$ ).

\section{Metodologia}

As características desta pesquisa são: é uma pesquisa qualitativa, a estratégia de pesquisa adotada é o estudo de caso comparativo, de natureza exploratória, com corte transversal e aproximação longitudinal. A unidade de análise são as práticas estratégicas e o nível de análise é individual e organizacional.

É importante evidenciar que em uma pesquisa qualitativa busca-se a compreensão dos agentes e daquilo que os levou singularmente a agir como agiram. Isso só é possível se os sujeitos forem ouvidos a partir da sua lógica e exposição de razões. Quando muito, pode-se identificar crenças mais ou menos compartilhadas por grupos sociais, ou seja, a cultura, sem pressupor que ela seja uma categoria estática no tempo e no espaço, mas uma categoria analítica em permanente transformação Sampaio (2001, apud GODOI; BALSINI, 2006).

Hinings (1997 apud BALOGUN; HUFF; JOHNSON, 2003) menciona que o estudo de caso é a abordagem típica da pesquisa processual. Em relação à natureza exploratória da pesquisa, cabe ressaltar que, segundo Patton (1990 apud GODOI; BALSINI, 2006), os métodos qualitativos são particularmente orientados para exploração, descoberta e lógica indutiva. A presente pesquisa adotou a perspectiva temporal de corte transversal com aproximação longitudinal, pois os dados foram coletados em um período específico e curto de tempo. Mas, como alguns dados coletados foram relativos a situações passadas e os entrevistados se referiram a fatos passados nas entrevistas, justifica-se a aproximação longitudinal. 
Como o objetivo deste trabalho foi explorar um fenômeno intersubjetivo e social, não houve a preocupação em comprovar e validar hipóteses, mas sim desenvolver uma leitura interpretativa e profunda para que fosse possível compreender como se dá a construção de sentidos pelos atores envolvidos nas práticas estratégicas. É importante realçar que, com o intuito de identificar casos típicos pertinentes ao objetivo proposto por essa pesquisa, foi feita uma seleção intencional. 0 critério para a seleção dos cursos de graduação em Administração estudados foi o reconhecimento e a qualidade dos cursos constatados em uma avaliação desenvolvida pelo MEC, em que os cursos de graduação em Administração da UFPR e da FAE obtiveram o conceito 5. Após a definição deste critério, verificou-se a possibilidade de acesso aos dois cursos, por meio de contatos iniciais via e-mail e que resultaram na aceitação por parte de ambos os cursos para que fosse desenvolvido o trabalho. Após a aprovação da pesquisa, os caminhos percorridos em cada um dos cursos foram: na UFPR, uma vez aprovada a pesquisa pela chefia do departamento, iniciaram-se as entrevistas no final de agosto de 2008; na FAE, a pesquisa foi aprovada perante uma carta formal encaminhada às instâncias responsáveis da instituição e foi necessário aguardar um retorno para que as entrevistas pudessem ser marcadas, o que aconteceu na segunda quinzena de outubro de 2008.

A partir da revisão de literatura da estratégia enquanto prática foi possível compreender que os participantes da pesquisa deveriam ser pessoas envolvidas com o conteúdo e o processo estratégico do curso, devendo atuar nas práticas e atividades estratégicas, ou seja, deveriam ser praticantes. Então, após a identificação dos praticantes - tanto professores/corpo diretivo, quanto alunos foram caracterizados como praticantes - tentou-se identificar aqueles que estavam mais envolvidos com o conteúdo e com o processo estratégico dos cursos pesquisados e, consequentemente, com as práticas e atividades estratégicas. No grupo de professores/corpo diretivo tentou-se cumprir esse critério ao selecionar aqueles que estão há mais tempo trabalhando no curso, estão envolvidos nas práticas e atividades estratégicas e, para que fosse possível obter uma compreensão mais ampla do grupo de professores/corpo diretivo, optou-se por selecionar professores de cada área: Marketing, RH, Tecnologia, Produção, etc. Já em relação ao grupo de alunos, para cumprir o critério, investigou-se o grupo dos alunos mais envolvidos e verificou-se que, na UFPR, os alunos que atuavam como representantes de turma e no período da manhã, eram os mais envolvidos. Na FAE, não foi possível entrevistar os representantes de turma, porém tentou-se entrevistar o maior número de alunos para se obter uma melhor compreensão do grupo de alunos da FAE, uma vez que a seleção destes não foi tão criteriosa. Verificouse também a necessidade de selecionar alunos de todos os períodos do curso (do $1^{\underline{0}}$ ao $4^{\circ}$ ano) para que também fosse possível obter uma compreensão ampla do grupo de alunos de cada curso. Este critério foi cumprido em ambos os casos.

Foram utilizadas algumas fontes para a coleta dos dados com o intuito de se obter a maior quantidade de informações possível capturadas de maneira diferenciada, com o objetivo de enriquecer a análise dos dados e também porque o estudo de caso tem uma capacidade de lidar com uma grande variedade de evidências (YIN, 2005). Neste estudo foram utilizados: documentos, entrevistas em profundidade (semiestruturadas) e observação direta. A coleta de dados iniciou-se por meio da obtenção de dados secundários - informações referentes aos dois cursos estudados - a fim de se compreender a dinâmica de cada um deles. Essas informações foram obtidas nos sites dos cursos. É relevante destacar que alguns dados secundários, como os documentos, foram coletados por meio de material impresso que as instituições disponibilizaram.

Em seguida, uma vez aprovada a pesquisa nos dois cursos selecionados, foram agendadas e realizadas as entrevistas em profundidade (semiestruturadas) com os praticantes identificados, somando um total de 34 entrevistas. Na UFPR realizou-se 15 entrevistas (11 com professores/corpo diretivo e 4 com alunos). Na FAE, realizou-se 19 entrevistas (11 com professores/corpo diretivo e 8 com alunos). A maioria dos participantes permitiu que a entrevista fosse gravada, com exceção de dois participantes: (1) um da UFPR permitiu que fosse gravada somente uma parte da entrevista e (2) um da FAE não permitiu que a entrevista fosse gravada; logo foram transcritas $32 \frac{1}{2}$ entrevistas. Convém salientar que foram feitas anotações durante as entrevistas com o intuito de auxiliar/complementar as transcrições e a análise dos dados. Durante as transcrições das entrevistas, procurou-se refletir sobre os dados e, de certa forma, configurar algumas análises. Após as transcrições das entrevistas, foi feita uma leitura detalhada 
do material transcrito e delineada a estrutura para o desenvolvimento da análise dos dados. É importante destacar que a análise de dados qualitativos não é a última fase do processo de pesquisa; ela é concomitante com a coleta de dados ou é cíclica (GODOY, 2006). Concomitantemente à realização das entrevistas, também foram feitas observações diretas, uma vez que ao estar inserido no ambiente de pesquisa, o pesquisador está constantemente observando o contexto no qual está inserido.

A natureza e os pressupostos desta pesquisa indicaram a importância de se fazer uma triangulação dos dados, fato este suprido por meio de uma triangulação entre pesquisadores, uma vez que os dados, apesar de utilizados para o desenvolvimento de duas pesquisas com focos diferentes, foram coletados conjuntamente. Logo após as entrevistas, os dados eram exaustivamente discutidos, interpretados e reinterpretados pelas duas pesquisadoras envolvidas.

\section{Análise dos dados}

Convém destacar que a análise dos dados foi desenvolvida com base na análise de narrativas, empreendendo-se assim duas narrativas, uma para cada caso. Em seguida, foi feita uma análise comparativa dos casos. Tendo em vista o escopo deste artigo, bem como o número máximo de páginas permitido, optou-se por focar na análise comparativa trazendo alguns elementos das narrativas que indicassem o que foi mais significativo. Diante disso, convém elucidar que, na análise comparativa dos casos, é possível compreender a discussão dos dados à luz do objetivo delineado para a pesquisa.

\section{Análise comparativa}

A análise comparativa é desenvolvida com base nas análises narrativas empreendidas para cada caso individualmente. As narrativas foram construídas separadamente para que as nuances dos dados fossem reveladas de forma única e específica.

\section{Quanto ao conteúdo e ao processo estratégico}

Primeiramente, observa-se na UFPR que, por se tratar de uma universidade pública, há uma dificuldade de inovar e mudar, uma vez que há um excesso de trâmites burocráticos para que isso seja feito, mas mesmo assim observa-se o interesse, por parte de alguns, de enfrentar a burocracia para atingir os seus objetivos e assegurar melhores condições para o curso. É interessante observar que apesar de dificultadores burocráticos, na universidade pública o ambiente é propício para discussões de caráter mais democrático, onde valores diferenciados emergem dada a natureza da instituição.

Na FAE, também se observa a vontade de inovar e mudar, porém, diferentemente da UFPR, isso se dá de maneira menos burocrática. A inovação e a mudança devem acontecer, com a condição de que seja favorável à instituição e que sejam alcançados resultados positivos. Por conta de ser uma instituição privada, na FAE é mais comum que haja uma coesão de significados, uma vez que as questões são discutidas, negociadas e, a partir daí, precisam ser aprovadas por instâncias específicas para que comecem a vigorar. Constata-se um acompanhamento próximo e um controle para que a coisas aconteçam.

Com relação à organização dos cursos, observa-se que na UFPR há uma falta de organização no que se refere à condução dos processos pedagógicos e administrativos - reestruturação da grade curricular, acompanhamento de conteúdo/ementa ministrado pelo professor, atendimento ao aluno, comunicação interna, definição de funções administrativas, entre outros. Percebe-se que devido à autonomia dispensada aos professores/corpo diretivo, muitas ações são desenvolvidas de forma independente e bastante individualizada. Não há um direcionamento comum. Os cargos administrativos são ocupados por professores e, ao fim do mandato, aquele professor que estava ocupando o cargo administrativo volta a atuar apenas como docente. Quando surgem problemas, momentos em que o coordenador e/ou chefe de departamento deve intervir e conversar com o professor, percebe-se que há um cuidado para não causar indisposições. Muitos desses problemas são relacionados à presença nas aulas, ao cumprimento do conteúdo das disciplinas e ao cumprimento de horário. Questões que sugerem a falta de comprometimento de alguns professores. Não fica claro, porém, qual o apoio e acompanhamento que a chefia/coordenação dá ao professor. 0 que pode ser observado também na pesquisa feita por Marra e Melo (2005):

quando convidados a falar sobre as estratégias que utilizavam no exercício da autoridade [...], 63,33\% 
dos entrevistados responderam que preferem conversar com os subordinados quando ocorre algum problema. A estratégia de conversar, de adotar uma postura mais democrática, vem reforçar a prática gerencial de evitar conflitos [...] (MARRA; MELO, 2005, p. 15).

Um dos entrevistados da UFPR salienta exatamente essa questão ao mencionar que:

o grande problema é que você não tem instrumentos de gestão. Porque o que é que funciona: olha, tomamos uma decisão e [...] digamos seria uma decisão estratégica. Para esta decisão estratégica ser implantada há que se ter um plano de trabalho. E esse plano de trabalho tem que ser executado por alguém. Na iniciativa privada se o alguém não executar isso, ele vai ser penalizado. Na iniciativa pública não existem instrumentos de penalização. Se você perguntar para um burocrata ele vai dizer "Ah, existe o processo administrativo", só que a universidade é corporativa e processos administrativos fogem do escopo de um professor que não cumpriu a sua carga horária você não vai fazer um processo administrativo para um professor que não cumpriu a sua carga horária. Então o que falta são instrumentos de gestão e um pouco de comprometimento das pessoas [...]. Até porque, vocês vejam a minha situação hoje, eu era chefe e voltei a ser peão [...] (ENTREVISTADO 06).

É importante que, mais uma vez, seja destacado o caráter público da UFPR, uma vez que existem instrumentos para afastar um professor, caso seja necessário, porém, segundo os entrevistados, utiliza-se o processo administrativo apenas quando o caso é bastante grave.

Na FAE, existe a mesma situação no que se refere aos cargos de chefia/coordenação também serem ocupados por professores. Todavia, percebe-se claramente que essa relação chefe/coordenador-professor acontece de forma diferente. Observa-se que há um grande apoio e respaldo da coordenação em relação às atitudes e decisões tomadas pelos professores em sala de aula, diferentemente da UFPR em que esse aspecto praticamente não é ressaltado pelo grupo de professores entrevistado, e, quando mencionado, percebe-se que não há muito respaldo. Além de mencionado pelos professores da FAE, os membros da coordenação também mencionam o apoio que é dado ao professor. Com isso, observa-se que há uma relação bastante harmoniosa entre coordenação-professor na FAE. Com relação ao coordenador que é professor e que um dia voltará a ser apenas professor, não há nem uma menção a essa questão, uma vez que o papel do coordenador é percebido e respeitado por todos e eles compreendem que é um trabalho coletivo no qual todos contribuem para a construção de um curso com qualidade. É importante ressaltar que na FAE, por ser um centro universitário privado, há maior controle em relação ao professor. Esse acompanhamento próximo que é feito com o docente garante que sejam mantidos aqueles que se encaixam no perfil de professor pretendido para o curso de Administração da FAE. Existem instrumentos de gestão claramente definidos e que são devidamente utilizados quando há necessidade.

Com relação ao perfil, não há um perfil único de professor na UFPR, visto que existem muitas diferenças entre eles (tempo em que estão na instituição, formação acadêmica e/ou profissional, regime de trabalho - 20h e 40h/DE, área de formação até comprometimento, posturas e visões diferentes). Na FAE, existe um perfil mais específico de professor, pois há uma predominância de professores que estejam atuando no mercado, e a sua grande maioria é bastante comprometida com as aulas, com os alunos e com a instituição, apesar de diferirem em relação ao tempo em que estão na instituição e à área de formação.

Ao falar em estratégia, observa-se que na UFPR não há uma percepção compartilhada em relação a essa questão; pelo contrário, existem concepções bastante distintas do que vem a ser a estratégia ou o conteúdo e o processo estratégico do curso de graduação em Administração da UFPR. Alguns dos entrevistados acreditam não haver uma estratégia formulada no curso de Administração da UFPR. Estes mencionam que não conseguem perceber um alinhamento estratégico (processo); para eles, não há nada formalmente formulado (conteúdo). Outros mencionam que não há um direcionamento estratégico nem uma estratégia formulada, apenas questões pontuais e/ou formais e ainda há um outro grupo que percebe uma estratégia formulada, apesar de não explícita ou não muito bem trabalhada, mas que atualmente há um esforço para se resgatar o alinhamento estratégico que existiu no passado, em que as estratégias foram claramente traçadas e o processo estratégico era bem conduzido, porém por uma série de acontecimentos e mudanças que ocorreram no curso ao longo dos anos houve uma dispersão, uma fragmentação 
do grupo de professores e isso acabou por prejudicar o processo estratégico. Esses pontos de vista extremamente distintos deixam transparecer a ambiguidade em relação à estratégia no curso de graduação em Administração. Percebe-se que não só a falta de comprometimento por parte tanto dos professores/ corpo diretivo quanto dos alunos, mas também as ausências de uma condução estratégia clara dificultam o processo e a definição do conteúdo estratégico como um todo, pois não se percebe a existência de um coletivo para que os esforços sejam direcionados a objetivos comuns e para que a qualidade do curso seja mantida/melhorada.

Na FAE, ao falar em estratégia, observa-se um direcionamento (processo) e um posicionamento (conteúdo) claros e sempre se menciona a questão da qualidade. Percebe-se que há um envolvimento de todos para atingir os objetivos comuns. No geral, a estratégia está clara não só para os professores/corpo diretivo, mas também para os alunos, uma vez que nas entrevistas percebe-se que essa questão é compartilhada. As decisões são tomadas com base no delineamento estratégico. Eles querem ter um curso de qualidade e reconhecido, desenvolver uma boa gestão, atrair e manter os melhores professores e formar o melhor profissional do mercado. Nota-se que todos os esforços são voltados para atingir esses objetivos: desde o desenvolvimento de uma reforma acadêmica bem estruturada e realizada com a participação de todos, passando pelo rigor na seleção e contratação de professores, pelo acompanhamento próximo do aluno até a disseminação de uma cultura consolidada e permeada pela tradição e pelos valores franciscanos. Diferentemente do curso de graduação da UFPR, o curso de graduação da FAE apresenta um conteúdo e um processo estratégico bem formulado e explícito.

\section{Quanto às práticas e atividades estratégicas}

Devido à estreita relação entre o conteúdo e o processo estratégico e às práticas e atividades estratégicas que são desenvolvidas, observa-se uma similaridade com relação ao que foi discutido no início desta seção, visto que é natural que haja uma coerência em relação a essas duas questões, pois uma vez que se tem um conteúdo e um processo estratégico bem definidos e bem conduzidos, além de as práticas e atividades estratégicas acontecerem em grande quantidade e de forma bem estruturada e organizada, há uma construção bastante clara de sentidos em relação a elas e, na sua maioria, os sentidos são compartilhados.

A análise dos dados desenvolvida na categoria professor/corpo diretivo da UFPR em relação às práticas e atividades estratégicas evidenciou que a maneira como os entrevistados constroem sentidos é diferente. Com isso, foi possível perceber três subgrupos: (1) aqueles que se interessam e se preocupam em atuar nas práticas e atividades estratégicas, entendendo-as como situações/oportunidades/ações importantes para desenvolver trocas de experiências, fomentar a aprendizagem, bem como negociar e legitimar objetivos individuais e coletivos; (2) aqueles que percebem as práticas como importantes, porém não se envolvem muito nem atuam de maneira plena e (3) aqueles que não há como perceber, de forma clara, o sentido que constroem em relação às práticas e atividades estratégicas, uma vez que não se aprofundam no tema. Com base na perspectiva da estratégia enquanto prática pode-se inferir que o strategizing, que é definido como a intersecção entre práticas, praticantes e prática, acontece para aqueles que fazem parte do subgrupo (1), por mais que na UFPR o fazer estratégia não aconteça de forma plena, devido às indefinições e dúvidas em relação à estratégia.

Traçando um paralelo com as concepções teóricas do sensemaking, observa-se que a construção de sentidos se dá de forma ampla e clara por aqueles que estão atuando plenamente no fazer estratégia, nas rotinas do dia a dia e nas interações com os outros, uma vez que o sensemaking é dinâmico e social. Observa-se um processo intersubjetivo que, para o praticante, se torna plausível uma vez que ele compreende a importância da sua atuação e da atuação dos outros nas práticas e atividades estratégicas. Nos outros subgrupos, percebe-se que, uma vez que não há uma atuação plena nas práticas e atividades, a construção de sentidos se dá de forma superficial ou praticamente não acontece, pois o praticante não desenvolve mecanismos de sensemaking (percepções, interações, interpretações) para tal. Já a análise dos dados desenvolvida na categoria aluno da UFPR em relação às práticas e atividades estratégicas evidenciou que a maneira como os entrevistados constroem sentidos é bastante semelhante. Todavia, foi possível observar pequenas diferenças em relação ao grau de envolvimento dos praticantes nessas práticas e atividades estratégicas. Como a maioria dos alunos atribui muita importância às práticas e atividades 
estratégicas e percebe-se que há uma atuação plena dos mesmos, também é possível constatar que a construção de sentidos acontece de forma ampla e clara devido à intensa atuação dos praticantes. Contudo, é importante ressaltar que no decorrer dos anos eles se tornam mais acomodados e desestimulados com o curso.

Ao tratar das práticas e atividades estratégicas na FAE, observa-se que também existem formas diferentes de construção de sentidos em relação a essas questões, porém existem menos subgrupos dentro de cada grupo de professores/corpo diretivo e grupo de alunos entrevistados. Nota-se uma questão bastante interessante: enquanto na UFPR existem mais subgrupos dentro de cada grupo e há uma quantidade relativamente parecida de membros em cada subgrupo, o que caracteriza uma diversidade ainda maior, uma vez que não há a predominância de um subgrupo que constrói sentidos da mesma forma, na FAE, há a predominância de um subgrupo no grupo de professores/corpo diretivo, por exemplo. Foram percebidos dois subgrupos dentro do grupo de professores/corpo diretivo da FAE: (1) os que constroem sentidos de maneira ampla e detalhada, demonstrando envolvimento e interesse e compreendendo o foco no mercado e a qualidade como conteúdo estratégico e (2) os que constroem sentidos de maneira semelhante aos do subgrupo (1), porém são professores/ corpo diretivo que ressaltam a questão da pesquisa (mencionam que não há um incentivo à pesquisa na FAE). Convém ressaltar que são poucos os entrevistados que compõem o subgrupo (2). Com relação ao grupo de alunos entrevistados, percebem-se dois subgrupos também e a construção de sentidos difere apenas no grau em que se dá essa construção, uma vez que alguns compreendem melhor, são mais envolvidos e estão há mais tempo atuando nas práticas e atividades estratégicas (subgrupo 1), enquanto os que compõem o subgrupo (2) são aqueles que constroem sentidos de forma mais superficial, porém existem dois detalhes que precisam ser destacados em relação a esse subgrupo: eles são em menor quantidade e estão há pouco tempo atuando no curso, ou seja, na FAE há a predominância de uma forma de construção de sentidos, o que caracteriza um compartilhamento desses sentidos e maior harmonia dos que compõem os subgrupos. Diante disso, pode-se inferir que na FAE a dimensão cultural foi observada como relevante para a construção do conteúdo e do processo estratégico do curso de graduação em Administração, uma vez que os valores franciscanos permeiam a instituição e são disseminados por aqueles que dela fazem parte, refletindo no delineamento e condução do conteúdo e do processo estratégico e, consequentemente, nas práticas e atividades estratégicas.

\section{Discussão dos resultados}

O presente trabalho foi desenvolvido com o objetivo de compreender os sentidos individuais e coletivos construídos pelos atores nas práticas e atividades estratégicas de um processo estratégico. Para tanto, considerou-se as perspectivas da estratégia enquanto prática e do sensemaking para construir as categorias de análise, nortear a coleta e a análise dos dados e auxiliar na interpretação do pesquisador. Procurou-se compreender como os atores envolvidos atuam nas práticas e atividades estratégicas, portanto como o fazer estratégia acontece no dia a dia dos cursos pesquisados e como o processo de construção de sentidos se dá, considerando as interações dos indivíduos e as propriedades que compõem o sensemaking.

Diante dessa proposta de investigação, observou-se que a questão do envolvimento e comprometimento dos praticantes nas práticas e atividades estratégicas está diretamente ligada à forma como eles constroem sentidos, revelando que quanto mais envolvidos e comprometidos eles estão, mais claramente se dá a construção de sentidos, pois os mecanismos de sensemaking são utilizados constantemente e de forma plena.

Com base nas concepções do sensemaking, foi possível observar a relevância de algumas de suas características com relação ao comprometimento dos praticantes, tais como: (1) o caráter retrospectivo do sensemaking foi percebido como importante, pois aqueles que são comprometidos com suas práticas e atividades estratégicas estão constantemente agindo e interpretando suas ações com base em ações passadas, processo este que auxilia na construção de sentidos e; (2) a questão de o sensemaking ser criado em ambientes sensatos, pode-se ressaltar que ao fazer parte da criação do ambiente, entendendo que este não se trata de uma entidade monolítica, há uma ênfase na agência do praticante e, consequentemente, há uma clara relação com o seu comprometimento, visto que seu papel na criação do ambiente faz com que ele se reconheça como relevante no processo. É interessante frisar que 
a questão envolvimento e comprometimento de sujeitos, comumente estudada no campo do comportamento organizacional, aparece nessa pesquisa de forma intrinsecamente ligada à estratégia.

Convém resgatar que foi considerada a concepção de Berger e Luckmann (2007) de que a realidade é socialmente construída e tentou-se compreender a dimensão cultural como processo de produção dessa realidade, uma vez que se pressupõe que, ao tratar de conteúdo e processo estratégico, é importante compreender como que a dimensão cultural é construída.

0 recorte da prática e, mais especificamente, da estratégia enquanto prática permitiu um olhar mais abrangente e complexo do objeto de estudo, uma vez que o trabalho não adotou um recorte formal e abstrato, comumente escolhido nas pesquisas do campo da estratégia. Uma vez proposto esse delineamento metodológico, foi possível perceber e revelar a dimensão cultural das instituições estudadas, bem como o seu processo de construção por meio das interações dos praticantes no dia a dia, das negociações de significados e dos valores individuais e institucionais percebidos nas entrevistas em profundidade. Com isso, é importante evidenciar que a lógica formal, o causalismo simples, não consegue revelar a dimensão cultural, visto que todo o emaranhado de questões que compõem a dimensão cultural de uma organização não é facilmente percebido, pois é continuamente construído e reconstruído pelos atores das organizações por meio das suas ações e interações.

Com base na análise comparativa empreendida, foi possível constatar inúmeras diferenças, principalmente no que se refere ao processo estratégico e à condução/desenvolvimento de práticas e atividades estratégicas. Observou-se que a inexistência de um direcionamento estratégico claramente definido e compreendido pelos atores envolvidos, como se observou no caso da UFPR, dificulta o andamento do processo estratégico como um todo, principalmente no que se refere às práticas e atividades estratégicas, que, consequentemente, acontecem de forma bastante "solta" e individualizada. Além disso, observou-se também que as dificuldades vivenciadas pela gestão, no que se refere à condução das suas atividades relacionadas ao corpo docente, são agravadas devido à ausência de um coletivo e de um maior entrosamento entre os pares.

Na FAE, observou-se que um alinhamento estratégico claramente definido e compartilhado por todos os envolvidos facilita o andamento do processo estratégico e das práticas e atividades estratégicas que o compõem, uma vez que essas são construídas e conduzidas com base em uma estratégia formulada e explícita. Além de se observar a flexibilidade para inovar e mudar - o que favorece o acolhimento de estratégias emergentes e de ideias interessantes -, então é possível observar a existência de um coletivo, uma vez que eles são empenhados em compartilhar experiências e materiais e trabalham para atingir um objetivo comum.

Todavia, com relação à natureza das instituições estudadas - uma pública e a outra privada -, existem diferenças importantes que precisam ser evidenciadas. O comprometimento dos que fazem parte de uma instituição privada se dá não só por razões individuais, ou seja, eles são comprometidos não apenas porque se importam com a formação do aluno e se esforçam para cumprir suas atividades de forma satisfatória, mas há um controle para que isso aconteça. Quando trataram deste assunto, os entrevistados da FAE mencionam a cultura da instituição como sendo bastante disseminada e intrínseca. É importante realçar que essa cultura é construída com base nos valores franciscanos disseminados entre professores/ corpo diretivo e alunos e com base na construção complexa que se dá no dia a dia do curso, por meio da interação dos envolvidos e do esforço para alcançar um objetivo comum.

Quando questionados sobre o ambiente/clima organizacional, os entrevistados revelaram uma grande satisfação em trabalhar e estudar na FAE. Alguns não souberam explicar exatamente o porquê de um ambiente tão harmonioso, simplesmente se referiram ao termo cultura; outros, além de mencionarem os valores franciscanos, recorreram a questões como: a integração dos professores e coordenadores e o apoio e comprometimento de todos. É importante destacar que a UFPR é uma IES pública onde a questão da pesquisa e extensão segue uma tradição e entende-se que também há uma preocupação em formar alunos para a atuação no mercado, porém não se trata de uma preocupação muito linear; diferentemente da FAE em que há um foco específico (foco no mercado). Assim, convém salientar que na IES pública há uma cultura acadêmica complexa e permeada por diversidades e contradições, uma vez que se trata de um ambiente mais democrático, enquanto na IES privada, a dimensão cultural é permeada por questões mais consensuais, uma vez que há um foco delineado.

Outra questão importante que merece ser destacada em relação ao contexto institucional das IES 
estudadas é que este contexto influenciou na formação das concepções dos entrevistados, muito porque tratam-se de diferentes condições e dimensões. É interessante observar que, na UFPR, há uma seleção rigorosa - vestibular - para entrar no curso, ou seja, há um aspecto externo muito forte nesse caso. 0 ambiente seleciona. Já no caso da FAE, o aluno não vem "pronto", ele é formado pela instituição; neste caso, o aspecto interno é que se sobressai. Questões como essas ajudam a explicar um pouco melhor a realidade estudada: (1) No decorrer dos anos, a insatisfação dos alunos da UFPR aumenta, pois eles entram no curso com uma expectativa muito alta e muitas vezes não são cobrados o suficiente e/ou suas competências não são exploradas; (2) Na FAE, o aluno precisa ser preparado para que ele saia da instituição pronto para atuar no mercado. É feito um trabalho contínuo para que esse aluno desenvolva competências, seja disciplinado e aprenda bastante. Diante disso, entende-se porque a maioria se compromete cada vez mais com o curso no decorrer dos anos.

\section{Considerações finais}

De acordo com as concepções teóricas de Weick (1979) sobre organizing, convém resgatar que ao construir sentido de determinada situação (práticas e atividades estratégicas, no caso deste estudo), os atores de uma organização passam a compreender as informações inerentes àquela situação - informações estas que eram ambíguas, mas deixam de ser ao serem interpretadas - facilitando o processo de organizing, uma vez que quando situações similares se repetirem, haverá um estoque de informações não ambíguas para serem utilizadas.

Assim, conclui-se que os praticantes mais envolvidos/comprometidos, aqueles que estão atuando plenamente nas atividades e práticas estratégicas, constroem sentido de forma clara e ampla, pois ao estarem constantemente absorvendo informações, empreendem o processo de diminuição da ambiguidade contida nessas informações, e, ao final, retêm as informações para uso futuro, movimentando assim o processo de organizing.

Finalmente, tendo em vista que estudos que adotam as abordagens da estratégia enquanto prática e do sensemaking conjuntamente ainda são incipientes e com o intuito de contribuir para uma melhor compreensão dessas abordagens teóricas, sugere-se que sejam empreendidos estudos: (1) mais específicos, focando em uma das categorias de entrevistados, por exemplo; (2) similares, mas que abordem as relações de poder, uma vez que no ambiente de IES e organizacional no geral essa questão é bastante presente; $\mathrm{e}$ (3) que investiguem mais detalhadamente a realidade do estrategista - como ele aprende e aplica seus conhecimentos sobre estratégia (teoria e prática).

\section{Referências}

ANSOFF, H. I. A nova estratégia empresarial. São Paulo: Atlas, 1990.

BALOGUN, J.; HUFF, A.; JOHNSON, P. Three responses to the methodological challenges of studying strategizing. Journal of Management Studies, v. 40, n. 1, p. 197-224, 2003.

BERGER, L.; LUCKMANN, T. A construção social da realidade: tratado de sociologia do conhecimento. 27. ed. Petrópolis: Vozes, 2007.

BRASIL. Conselho Nacional de Educação. Resolução n. 4, de 13 de julho de 2005. Institui as diretrizes curriculares nacionais do curso de graduação em administração, bacharelado. Diário Oficial da União, Brasília, DF, 19 jul. 2005. Seção 1, p. 26.

CHAKRAVARTHY, B.; WHITE, R. Strategy process: forming, implementing and changing strategies. In: PETTIGREW, A.; THOMAS, H.; WHITTINGTON, R. Handbook of strategy and management. London: Sage, 2002. p. 183-205.

GIOIA, D.; CHITTIPEDDI, K. Sensemaking and sensegiving in strategic change initiation. Strategic Management Journal, v. 12, n. 6, p. 433-448, 1991.

GODOY, A. Estudo de caso qualitativo. In: GODOI, C. K.; BANDEIRA-DE-MELLO, R.; SILVA, A. B. da (Org.). Pesquisa qualitativa em estudos organizacionais: paradigmas, estratégias e métodos. São Paulo: Saraiva, 2006. p. 1-13.

GODOI, C. K.; BALSINI, C. A pesquisa qualitativa nos estudos organizacionais brasileiros: uma análise bibliométrica. In: GODOI, C. K.; BANDEIRA-DE-MELLO, R.; SILVA, A. B. da (Org.). Pesquisa qualitativa em estudos organizacionais: paradigmas, estratégias e métodos. São Paulo: Saraiva, 2006. p. 89-114.

HENDRY, J.; SEIDL, D. The structure and significance of strategic episodes: social systems theory and the routine practices of strategic change. Journal of Management Studies, v. 40, n. 1, p. 175-196, 2003. 
JARZABKOWSKI, P. Strategy as practice: an activity-based approach. London: Sage, 2005.

JARZABKOWSKI, P.; BALOGUN, J.; SEIDL, D. Strategizing: the challenges of a practice perspective. Human Relations, v. 60 , n. 1 , p. 5-27, 2007.

JOHNSON, G. et al. Strategy as practice: research directions and resources. New York: Cambridge University Press, 2007

MARRA, A. V.; MELO, M. C. de O. L. A prática social de gerentes universitários em uma instituição pública. Revista de Administração Contemporânea, v. 9, n. 3, p. 9-31, 2005.

PETTIGREW, A. M. The character and significance of strategy process research. Strategic Management Journal, v. 13, p. 5-16, 1992.

SILVA, M. R.; FISCHER, T. Ensino de administração: um estudo da trajetória curricular de cursos de graduação. In: ENCONTRO DA ASSOCIAÇÃO NACIONAL DE PÓSGRADUAÇÃO E PESQUISA, 32., 2008, Rio de Janeiro. Anais... Rio de Janeiro: EnANPAD, 2008.

WEICK, K. E. The social psychology of organizing. Reading: Addison-Wesley, 1979.
WEICK, K. E. Sensemaking in organizations. Thousand Oaks: Sage Publications, 1995.

WEICK, K. E.; SUTCLIFFE, M.; OBSTFELD, D. Organizing and the process of sensemaking. Organization Science, v. 16, n. 4, p. 409-421, 2005.

WHITTINGTON, R. Completing the practice turn in strategy research. Organization Studies, v. 27, n. 5, p. 613-634, 2006.

YIN, R. K. Estudo de caso: planejamento e métodos. 3. ed. Porto Alegre: Bookman, 2005.
Recebido: 05/09/2011

Received: 09/05/2011

Aprovado: 11/10/2011

Approved: 10/11/2011 